\title{
MaXimización de Utilidades o InCREMENTo del VALOR DEL ACCIONISTA?
}

\author{
Raúl Arrarte Mera \\ Facultad Ciencias Económicas de la UNMSM \\ Lima - Peru
}

\begin{abstract}
RESUMEN
La manera más efectiva de obtener y mantener la concentración de los directivos y gerentes en la excelencia de gestión, es mediante la Administración Centrada en Principios. En este aspecto la aplicación de los principios de contabilidad generalmente aceptados como: consistencia o uniformidad, importancia relativa, prudencia y el costo como base de valuación, resultan fundamentales en la aplicación de políticas coherentes para la organización.
\end{abstract}

Palabras clave: Oportunidad, Flujos, riesgo, riqueza

\section{INTRODUCCION}

En qué consiste ésta? ¿Cuál es su objetivo?. Su objetivo es, permitir una concentración más rápida y fuerte para el logro de las metas corporativos. Lograr esa rapidez y fortaleza requiere de armonía y equilibrio, y a su vez lograr esta armonía y equilibrio precisa de concentración.

\section{EL MITO DE LA MAXIMIZACIÓN DE LAS UTILIDADES.}

Por lo general, los propietarios de una sociedad anónima no son sus administradores. Por lo tanto, los administradores financieros o la gerencia financiera, necesitan saber cuáles son los objetivos de los propietarios de la empresa. Algunas personas creen, en el enfoque tradicional de las finanzas, que el objetivo de la empresa es siempre maximizar las utilidades. En este afán, la gerencia financiera tomará solamente las acciones que se esperaría que hicieran una contribución importante a las utilidades totales de la empresa. $\mathrm{Y}$ de todas las alternativas que se
En este artículo se pretende demostrar que existe armonía y equilibrio cuando los objetivos y las metas de la empresa se orientan hacia la maximización de la riqueza de los accionistas. Y ocurre lo contrario, cuando solamente está orientada a la maximización de las utilidades.

consideren, veces perdiendo la perspectiva del largo plazo y deteriorando la estructura de financiamiento del capital propio.

Pero, ¿la maximización de utilidades es un objetivo razonable?. No, fracasa por varias razones porque ignora:

1) La oportunidad de los rendimientos.

2) Los flujos de efectivo disponible para los accionistas, $y$

3) El riesgo.

Desde el punto de vista de la Oportunidad de los rendimientos, es preferible que ocurra más temprano que tarde. Esto es que los rendimientos mayores en el año 1 se podrían reinvertir para proporcionar mayor ganancias en el futuro. Siempre y cuando que dichos rendimientos 
superen el costo de capital. Por lo contrario estaríamos descapitalizando la empresa, y no precisamente creando valor para el accionista, al retirar su capital y no los rendimientos. Este tema lo explicaremos más adelante con un ejemplo.

Con referencia al Flujo de Efectivo disponible para el accionista, las utilidades no necesariamente dan como resultado flujos de efectivo para su beneficio. Este flujo reciben los propietarios ya sean en efectivo en forma de dividendo o de los beneficios por la venta de sus acciones a un precio más alto que el pagado inicialmente. Mayores utilidades por acción no necesariamente significan que la asamblea de accionistas votará para incrementar los pagos de dividendos. Asimismo, mayores utilidades por acción no necesariamente se traducen en un precio accionario más alto. A veces las empresas tienen aumentos en sus ganancias sin que haya ningún cambio favorable en correspondencia con el precio de las acciones. Esto ocurre sólo cuando "los incrementos de las ganancias están acompañados de flujos de efectivo futuros incrementados, se esperará un precio accionario más alto" (').

Una premisa básica en la administración financiera es que hay una compensación entre el rendimiento (flujo de efectivo) y el riesgo. Rendimiento y riesgo son en realidad los principales determinantes del precio de las acciones, el cual representa la riqueza de los propietarios en la empresa. En general los accionistas, son adversos al riesgo, es decir, prefieren evitar el riesgo. Cuando se implica riesgo, los accionistas esperan ganar tasas más altas de rendimientos sobre inversiones de riesgo más alto y tasas más bajas sobre inversiones de riesgo más bajas.

Puesto que la maximización de las utilidades no consigue los objetivos de los propietarios de la empresa, no debería ser el objetivo de la gerencia financiera.

\section{MAXIMIZACIÓN DE LA RIQUEZA DELOS ACCIONISTA}

El objetivo de la empresa $y$, por consiguiente, el de toda gerencia financiera, es maximizar la riqueza de los propietarios para quienes se trabaja. La riqueza de los propietarios corporativos se mide por el precio de las acciones, que a su vez se basa en la oportunidad de los rendimientos, su magnitud y su riesgo. Al considerar cada alternativa de decisión en términos de su impacto sobre el precio de las acciones de la empresa, los gerentes financieros sólo deben aceptar aquellas decisiones que se espera que incrementen el precio de las acciones. Puesto que el precio de las acciones representa la riqueza de los propietarios en la empresa: la maximización del precio de las acciones maximizará la riqueza del propietario.

ANEXO No. 1. ANÁLISIS ESTRUCTURAL (MILES DE USS).

\begin{tabular}{|c|c|c|c|c|c|c|}
\hline CONCEPTOS & $20 \overline{05}$ & & 2004 & $(\%)$ & VARIACION & \\
\hline \multicolumn{7}{|c|}{ INVERSIONES } \\
\hline Activo Corriente & $1 ' 280,260$ & 74.94 & 837,682 & 76.53 & 442.578 & 72.10 \\
\hline $\begin{array}{l}\text { Activo No } \\
\text { Corriente }\end{array}$ & 428,170 & 25.06 & 256,870 & 23.47 & 161,300 & 27.90 \\
\hline TOTAL & $1 ' 708,430$ & 100.00 & $1{ }^{\prime} 094,552$ & 100.00 & 613,878 & \\
\hline \multicolumn{7}{|c|}{ FINANCIAMIENTO } \\
\hline Capital Ajeno & 675,341 & 39.53 & 310.033 & 28.32 & 365.308 & 59.51 \\
\hline Capital Propio & I'033.089 & 60.47 & 784,519 & 71.67 & 248,570 & 40.49 \\
\hline TOTAL & I'708,430 & 100.00 & 1.094 .552 & 100.00 & 613.878 & 100.00 \\
\hline
\end{tabular}


superen el costo de capital. Por lo contrario estaríamos descapitalizando la empresa, y no precisamente creando valor para el accionista, al retirar su capital y no los rendimientos. Este tema lo explicaremos más adelante con un ejemplo.

Con referencia al Flujo de Efectivo disponible para el accionista, las utilidades no necesariamente dan como resultado flujos de efectivo para su beneficio. Este flujo reciben los propietarios ya sean en efectivo en forma de dividendo o de los beneficios por la venta de sus acciones a un precio más alto que el pagado inicialmente. Mayores utilidades por acción no necesariamente sıgnifican que la asamblea de accionistas votará para incrementar los pagos de dividendos. Asimismo, mayores utilidades por acción no necesariamente se traducen en un precio accionario más alto. A veces las empresas tienen aumentos en sus ganancias sin que haya ningún cambio favorable en correspondencia con el precio de las acciones. Esto ocurre sólo cuando "los incrementos de las ganancias están acompañados de flujos de efectivo futuros incrementados, se esperará un precio accionario más alto" $\left({ }^{1}\right)$.

Una premisa básica en la administración financiera es que hay una compensación entre el rendimiento (flujo de efectivo) y el riesgo. Rendimiento y riesgo son en realidad los principales determinantes del precio de las acciones, el cual representa la riqueza de los propietarios en la empresa. En general los accionistas, son adversos al riesgo, es decir, prefieren evitar el riesgo. Cuando se implica riesgo, los accionistas esperan ganar tasas más altas de rendimientos sobre inversiones de riesgo más alto y tasas más bajas sobre inversiones de riesgo más bajas.

Puesto que la maximización de las utilidades no consigue los objetivos de los propietarios de la empresa, no debería ser el objetivo de la gerencia financiera.

\section{MAXIMIZACIÓN DE LA RIQUEZA DELOS ACCIONISTA}

El objetivo de la empresa y, por consiguiente, el de toda gerencia financiera, es maximizar la riqueza de los propietarios para quienes se trabaja. La riqueza de los propietarios corporativos se mide por el precio de las acciones, que a su vez se basa en la oportunidad de los rendimientos, su magnitud y su riesgo. Al considerar cada alternativa de decisión en términos de su impacto sobre el precio de las acciones de la empresa, los gerentes financieros sólo deben aceptar aquellas decisiones que se espera que incrementen el precio de las acciones. Puesto que el precio de las acciones representa la riqueza de los propietarios en la empresa: la maximización del precio de las acciones maximizará la riqueza del propietario.

ANALISIS ESTRUCTURAL (MILES DE USS).

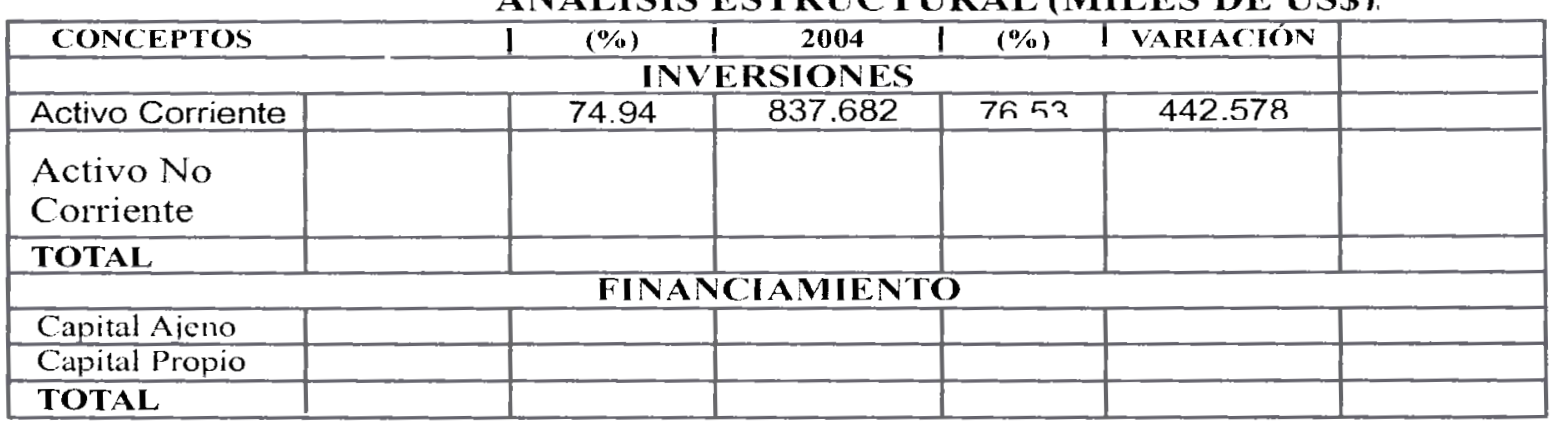


El análisis de esta estructura nos muestra una empresa, que siendo industrial, presenta la estructura de una típica empresa comercial, que prioriza el corto plazo en vez del largo plazo. El período bajo análisis, muestra un crecimiento de inversiones equivalente al $56 \%$ del 2005 . De los cuales 442 millones de dólares los destinó al corto plazo (72.10\%), y el saldo de 161 millones, al largo plazo (27.90\%).

Este gran crecimiento, sin embargo, fue financiado apoyado en el capital ajeno, que se vio fortalecido en el año corriente al aumentar su posición $28.33 \%$ al $39.53 \%$. Mientras que en la misma proporción disminuía el capital propio al caer de $71.67 \%$ a $60.47 \%$. Cuyo efecto más notable se observa en el alza de los gastos financieros que muestra el Cuadro de Ganancias y Pérdidas, que aquí omitimos donde los Gastos por Intereses pasaron de más de 10 millones a más de 27 millones de dólares, arrastrando también en la caída en las Utilidades por Acción de US\$ 6.42 a US\$ 3.77 .

Pese al gran incremento en las ventas de $35.72 \%$ respecto del año anterior, notamos que la rentabilidad ha disminuido, tanto a nivel de activos, de patrimonio neto y sobre las ventas netas. Sin embargo, es una importante utilidad que no puede pasar desapercibido: un significativo $28 \%$ anual.

Si bien es cierto que desde el punto de vista de rentabilidad ésta se ha mantenido en el mismo nivel del año anterior, la posición financiera de la empresa para el largo plazo, se ha deteriorado, conforme se muestra en el Anexo No. 1, la estructura del financiamiento.

\section{CONCLUSIONES}

1. Para que una gestión económicofinanciera sea armónica y equilibrada sus índices estructurales deben mostrar crecimiento tanto cuantitativa como cualitativamente de un año a otro. Cuya mayor fortaleza se mostrará en las utilidades significativas que mostrará el Estado de Ganancias y Pérdidas.

2. Es más importante el crecimiento relativo que el cuantitativo. Si maximizamos la riqueza de los accionistas, estamos asegurando el futuro de la empresa en el largo plazo. De lo contrario estaremos mostrando una debilidad por el lento pero continuo fortalecimiento del capital ajeno.

3. No es suficiente generar rentabilidad si esta no se ve reflejada en el incremento del de la riqueza de los accionistas en la estructura de financiamiento. Si se acordara una distribución de dividendos, bajo estas condiciones, estaremos repartiendo nuestro propio capital y las utilidades generadas por el negocio.

4. Una medida correctiva en estas circunstancias sería, sencillamente, la capitalización de las utilidades.

\section{REFERENCIAS}

1. Lawrence J. Gitman. "Principios de Administración Financiera". Décima Edición. Editorial Pearson Educación. Año 2003. México. 